\title{
Glomerular Actions of Endothelin In Vivo
}

Valentina Kon, Toshimasa Yoshioka, Agnes Fogo, ${ }^{\star}$ and lekuni Ichikawa

Departments of Pediatrics and *Pathology, Vanderbilt University School of Medicine, Nashville, Tennessee 37232

\begin{abstract}
In Munich-Wistar rats, a micropipette was inserted into a first-order branch of the left main renal artery and continuously infused with human/porcine endothelin $(0.4 \mathrm{ng} / \mathrm{min})$. Micropuncture measurements revealed substantial differences within the cortical microcirculation of the same left kidney: SNGFR was some 35\% lower in glomeruli exposed to endothelin compared with non-endothelin-perfused glomeruli (P $<0.005)$. Similarly, glomerular plasma flow rate was some $38 \%$ lower in the endothelin-exposed glomeruli $(P<0.001)$. The hypoperfusion and hypofiltration in the endothelin-exposed glomeruli reflected an increase in resistances in the afferent and efferent arterioles. There was no difference in the value of the glomerular capillary ultrafiltration coefficient between the two populations of glomeruli.

We also studied kidneys that underwent $25 \mathrm{~min}$ of renal artery clamping $48 \mathrm{~h}$ before study. Antiendothelin antibody infused into one of the branches of the main renal artery ameliorated the vasoconstriction characteristic of postischemic nephrons: within the cortical microcirculation, the SNGFR in glomeruli exposed to antiendothelin antibody was $27.0 \pm 3.1$ $\mathrm{nl} / \mathrm{min}$ as compared with $17.4 \pm 1.7$ measured in glomeruli not perfused with the antibody $(P<0.001)$. Similarly, glomerular plasma flow rate was higher in the glomeruli exposed to antiendothelin antibody $(128.7 \pm 14.4 \mathrm{nl} / \mathrm{min}$ vs. $66.6 \pm 5.6, P$ $<0.005)$. Resistances in both the afferent and efferent arterioles were substantially lower in the antibody-exposed glomeruli. It is, therefore, suggested that endothelin, presumably released from damaged endothelium, may play an important intermediary role in the hypoperfusion and hypofiltration observed in postischemic kidneys.
\end{abstract}

\section{Introduction}

Vasomotor tone is controlled by dynamic interplay of neurogenic and myogenic mechanisms and circulating hormones. In the last several years, evidence has accumulated that the endothelium elaborates both vasoconstrictive and vasodilative substances, thereby participating in this dynamic regulation of vascular tone. Yanagisawa et al. isolated a vasoconstrictive substance from the supernatant of cultured porcine aortic en-

Presented in part at the Annual Meeting of the American Society of Nephrology, San Antonio, TX, December 1988 and published in abstract form in 1989. Kidney Int. 35:410. (Abstr.)

Address reprint requests to Valentina Kon, Assistant Professor of Pediatrics, Division of Pediatric Nephrology, Vanderbilt University School of Medicine, Nashville, TN 37232-2584.

Received for publication 30 December 1988 and in revised form 21 February 1989.

J. Clin. Invest.

(C) The American Society for Clinical Investigation, Inc.

0021-9738/89/05/1762/06 \$2.00

Volume 83, May 1989, 1762-1767 dothelial cells (1). It is a 21 -amino acid peptide with a structure different from any previously described mammalian peptides having homology with certain neurotoxins, e.g., scorpion venom and venom from the burrowing asp, Atractaspis engaddenis (1-3). Studies in strips of porcine coronary artery, rat aorta, basilar and renal arteries, rabbit and dog mesenteric arteries, and human pulmonary and mesenteric arteries, as well as other isolated tissues, show it to be a potent vasoconstrictor, having more vasoconstrictive activity than angiotensin II, vasopressin, or neuropeptide Y (1). We describe the in vivo effects of this vasoconstrictor on the renal cortical microcirculation. To minimize its effects on nonrenal organs, a microperfusion system was devised for infusion of endothelin into one of the three first-order branches of the main renal artery. This technique permits comparison of hemodynamics of treated and untreated populations of glomeruli within the same kidney. In addition, the pathophysiologic role of endogenous endothelin was evaluated in postischemic kidneys typified by persistent microcirculatory vasoconstriction. For this purpose, endothelin antibody was infused into a renal artery branch of kidneys previously exposed to an ischemic insult, and the glomerular hemodynamics of the infused nephrons were compared with those not infused with the antibody.

\section{Methods}

All experiments were done in male Munich-Wistar rats weighing $180-230 \mathrm{~g}$. The animals were allowed access to standard rat chow and tap water until the day of the experiment. Group 1 animals consisted of seven normal rats. The animals were prepared for micropuncture as previously described (4-6). Briefly, under anesthesia (70 mg Inactin $/ \mathrm{kg}$ body wt i.p.; BYK, FRG) tracheostomy was performed and indwelling polyethylene catheters were inserted into the femoral artery and vein and jugular vein for blood sampling, monitoring of systemic blood pressure, infusion of plasma, and inulin as previously described (4-6). In addition, one of the main branches of the left main artery was gently isolated. Care was taken not to disrupt the renal nerves and lymphatics. This branch vessel was momentarily $(<5 \mathrm{~s})$ occluded with fine forceps and distribution of its blood flow was marked on the surface of the kidney with a permanent ink marker by noting the blanching of the kidney surface. Using micropuncture techniques previously described in detail (4-6), measurements and collections were made in nephrons located within the area supplied by the isolated branch of the renal artery as well as nephrons outside of this area. Determination of single nephron glomerular filtration rate (SNGFR), ${ }^{1}$ hydraulic pressures in

1. Abbreviations used in this paper: $C_{\mathrm{A}}$, femoral arteriolar plasma protein; $C_{\mathrm{E}}$, efferent arteriolar plasma protein; $\Delta P$, transcapillary hydraulic pressure difference; $E_{\mathrm{A}}$, hydraulic pressure in efferent arteriole; $K_{\mathrm{f}}$, ultrafiltration coefficient; $P_{\mathrm{GC}}$, hydraulic pressure in glomerular capillaries; $P_{\mathrm{T}}$, hydraulic pressure in tubules; $\pi_{\mathrm{A}}$, colloid osmotic pressure of plasma entering glomerular capillaries; $\pi_{\mathrm{E}}$, colloid osmotic pressure of plasma leaving glomerular capillaries; $Q_{\mathrm{A}}$, glomerular plasma flow rate; $R_{\mathrm{A}}$, resistance of afferent arterioles; $R_{\mathrm{E}}$, resistance of efferent arterioles; SNGFR, single nephron glomerular filtration rate. 
glomerular capillaries $\left(P_{\mathrm{GC}}\right)$, tubules $\left(P_{\mathrm{T}}\right)$, and efferent arterioles $\left(E_{\mathrm{A}}\right)$; femoral arteriolar $\left(C_{\mathrm{A}}\right)$, and efferent arteriolar $\left(C_{\mathrm{E}}\right)$ plasma protein concentrations were made that permit calculation of glomerular plasma flow rate $\left(Q_{A}\right)$, transcapillary hydraulic pressure difference $(\Delta \mathrm{P})$, ultrafiltration coefficient $\left(K_{\mathrm{f}}\right)$ as well as resistances of the afferent $\left(R_{\mathrm{A}}\right)$ and efferent $\left(R_{\mathrm{E}}\right)$ arterioles. Colloid osmotic pressure of plasma entering $\left(\pi_{\mathrm{A}}\right)$ and leaving $\left(\pi_{\mathrm{E}}\right)$ glomerular capillaries were estimated from $C_{\mathrm{A}}$ and $C_{\mathrm{E}}$ using derivations of Deen et al. (6).

After baseline measurements and collections from areas of the kidney supplied by the isolated artery branch as well as areas supplied by the other two branches of the main renal artery, human/porcine endothelin $(0.4 \mathrm{ng} / \mathrm{min}$; Peptides International, Louisville, KY) was infused. This dose was chosen because higher doses of endothelin $(0.8-4.0 \mathrm{ng} / \mathrm{min})$ caused a marked vasoconstriction of the infused portion of the kidney, sufficient to blanch the surface of the kidney (Fig. 1). The infusion was accomplished through a sharpened micropipette with a $20-30-\mu \mathrm{m}$ opening, mounted to a micromanipulator and connected by polyethylene tubing to a syringe microinfusion pump (model 22; Harvard Instruments, S. Natick, MA). The pipette was advanced through the wall of the previously isolated branch of the renal artery and the infusion continued at a rate of $0.3 \mathrm{ml} / \mathrm{h}$. The infusion pump was calibrated in vitro as we have previously described (7). After $20 \mathrm{~min}$, repeat micropuncture measurements and collections were obtained from areas infused with endothelin and those regions of the kidney not infused with endothelin. In another five rats, we infused PBS in a manner identical to that described for endothelin.

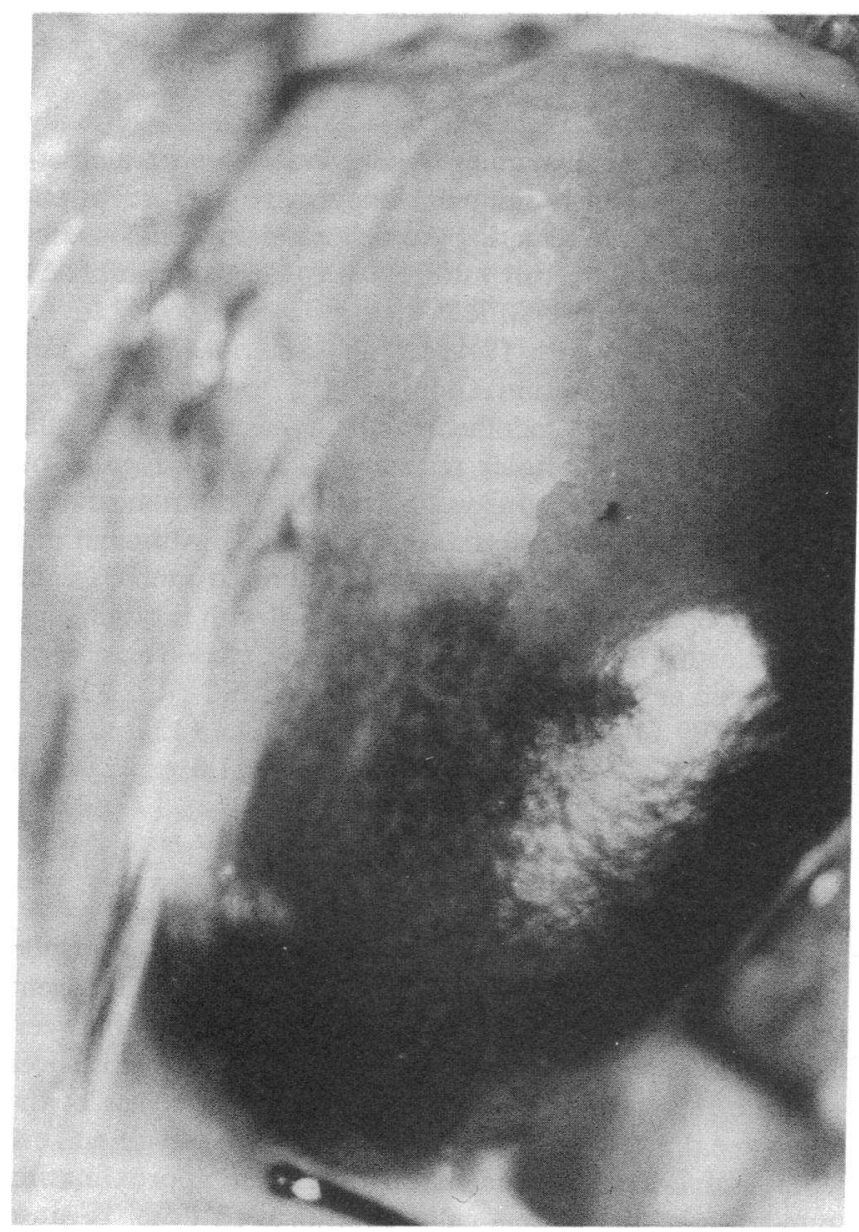

Figure 1. Appearance of the kidney during infusion of endothelin (2 $\mathrm{ng} / \mathrm{min}$ ) into the inferior branch of the main renal artery. The area of the kidney supplied by this vessel is profoundly vasoconstricted (blanching of the kidney surface).
Systemic endothelin has been observed to alter renal function in association with perturbations in systemic circulatory hemodynamics. To assess potential intermediary actions of angiotensin II (AII) in nephrons exposed to endothelin during branch infusion of endothelin, we duplicated the above described protocol during infusion of an AII antagonist (group 1A, $n=6$ ): the animals were prepared identically to those in group 1 except for infusion of $\operatorname{Sar}^{1}-\mathrm{Thr}^{8} \mathrm{~A}$ II $(0.1 \mu \mathrm{g} / \mathrm{kg}$ body wt/min i.v.; Sigma Chemical Co., St. Louis, MO) that started $1 \mathrm{~h}$ before and continued during micropuncture measurements and collections.

Group 2 consisted of seven Munich-Wistar rats that underwent renal artery occlusion. Under anesthesia $(70 \mathrm{mg} \mathrm{Nembutal} / \mathrm{kg}$ body wt i.p., Abbott Laboratories, Chicago, IL), each rat had a midline abdominal incision. The most proximal portion of the renal artery was easily isolated and clamped with a hemostatic clip for $25 \mathrm{~min}$. The removal of the clip was followed by prompt renal reperfusion. The abdomen was then closed, and when the animals recovered from anesthesia, they were returned to their cages and allowed to eat and drink freely as before. $48 \mathrm{~h}$ later, under Inactin anesthesia, these animals were prepared for micropuncture study as in group 1 study, including isolation of one of the branches of the left main renal artery. After the initial micropuncture measurements and collections, endothelin antibody was infused through the renal artery branch. The antiserum (Peptides International) is directed against human/porcine endothelin and raised in rabbits. This preparation of antiserum has $100 \%$ cross-reactivity with rat endothelin. A 1:10,000 dilution of the antiserum binds to $\sim 50 \%$ of the radiolabeled endothelin at a concentration of $1.3 \mathrm{pmol} /$ $\mathrm{ml}$. The antiserum was diluted 1:100 with phosphate buffer solution (pH 7.40) and infused at $1.6 \mathrm{nl} / \mathrm{min}$ through a micropipette infusion system described above for endothelin infusion. After $20 \mathrm{~min}$, micropuncture measurements and collections were again repeated in nephrons of the nonperfused areas and antiserum-perfused regions of the kidney. In five separate normal rats, nonimmunized rabbit serum was infused in a manner identical to that described for endothelin and endothelin antibody.

Fig. 2 schematically illustrates the infusion technique that permitted sections of a given kidney to be presented with either endothelin or endothelin antibody while other parts of that same kidney were not directly exposed to these substances. The label "Glomeruli I", thus represents the population of glomeruli of a normal kidney that were not exposed to endothelin, whereas "Glomeruli II" are glomeruli that were infused with endothelin. Similarly, "Glomeruli III" represent glomeruli from kidneys that $48 \mathrm{~h}$ before micropuncture underwent 25 min of ischemia and during the micropuncture experiments were not exposed to endothelin antibody. "Glomeruli IV" are glomeruli of the same postischemic kidneys but ones that were infused with endothelin antibody. For clarity, these labels for the different nephron populations are used in Table I.

Analytical. Plasma inulin concentrations were determined by the macroanthrone method (8). Details of the analytical procedure for inulin determination in nanoliter samples, $C_{\mathrm{A}}$ and $C_{\mathrm{E}}$ measurements are described elsewhere $(6,9,10)$. The volume of fluid collected from individual proximal tubules by micropuncture study in groups 1 and 2 were estimated from the length of fluid columns in a constant bore capillary tube of known internal diameter.

Statistics. Results are expressed as mean \pm SE. Differences between the two periods in groups 1 and 2 were compared by paired $t$ test. Intergroup differences were tested by analysis of variance with Bonferroni's method (11). The results were taken as statistically significant when $P$ value was $<0.05$.

\section{Results}

Table I summarizes the systemic and microcirculatory parameters after infusion of endothelin into one of the branches of the main renal artery of normal kidneys. The dose of endothelin used in the study was without effects on the systemic blood 
pressure or arterial hematocrit. Within the kidney, however, striking differences were observed in nephrons infused with endothelin versus those nephrons not exposed to this substance. In Glomeruli I (not exposed to endothelin) the SNGFR averaged $35.9 \pm 4.3 \mathrm{nl} / \mathrm{min}$, whereas in Glomeruli II (infused with endothelin) SNGFR was $23.5 \pm 3.1$. The glomerular plasma flow rate, $Q_{\mathrm{A}}$, also fell dramatically in response to endothelin. In Glomeruli $\mathrm{I}, Q_{\mathrm{A}}$ was, on average, $153.0 \pm 22.9$ $\mathrm{nl} / \mathrm{min}$ vs. $95.9 \pm 10.1$ in Glomeruli II. The microcirculatory values in Glomeruli I are typical of those previously reported in normal euvolemic rats (12). The hypoperfusion and hypofiltration in Glomeruli II were reflected in significantly higher arteriolar resistances: values for afferent arteriolar resistance, $R_{\mathrm{A}}$, averaged $0.35 \pm 0.06 \mathrm{~min} \cdot \mathrm{mmHg} / \mathrm{nl}$, a value significantly higher than the average of $0.21 \pm 0.03$ in nonperfused nephrons. Similarly, the value of efferent arteriolar resistance, $R_{\mathrm{E}}$, in Glomeruli II averaged $0.22 \pm 0.03 \mathrm{~min} \cdot \mathrm{mmHg} / \mathrm{nl}$ vs. $0.15 \pm 0.02$ in Glomeruli I. No difference was detected in the value of the glomerular capillary ultrafiltration coefficient, $K_{\mathrm{f}}$, between the two populations of glomeruli. SNGFR values measured in Glomeruli II before endothelin infusion and those in Glomeruli I during endothelin infusion were essentially identical. Thus, SNGFR of Glomeruli II before any endothelin was $32.3 \pm 4.2 \mathrm{nl} / \mathrm{min}$ and significantly higher than $23.5 \pm 3.1$ found in the same population of glomeruli during the endothelin infusion. In five separate rats (body wt $207 \pm 7$ g), infusion of saline, instead of endothelin, caused no change in systemic or microcirculatory values: SNGFR $35.8 \pm 6.3$ vs. $36.8 \pm 5.7 \mathrm{nl} / \mathrm{min} ; Q_{\mathrm{A}} 142.7 \pm 35.7$ vs. $136.5 \pm 23.7 \mathrm{nl} / \mathrm{min} ; P_{\mathrm{GC}}$ $50.6 \pm 1.0$ vs. $51.0 \pm 1.0 \mathrm{mmHg} ; P_{\mathrm{T}} 13.0 \pm 1.0$ vs. $13.0 \pm 1.0$ $\mathrm{mmHg}$.

To evaluate potential intermediary actions of AII in this vasoconstrictor response to endothelin we repeated the renal artery branch infusion of endothelin during systemic intravenous administration of $\mathrm{Sar}^{1}-\mathrm{Thr}^{8}$ AII. Again, there was no change in the systemic blood pressure or arterial hematocrit. The decrease in SNGFR in glomeruli infused with endothelin during AII inhibition versus with glomeruli not exposed to

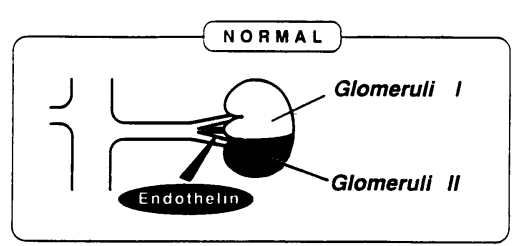

Figure 2. Schematic illustration of the infusion technique and different nephron populations undergoing various treatments. (Top) A normal kidney undergoing infusion of endothelin into one of the branches of the main renal artery while other parts of that same kidney remained unexposed to this substance. Glo-

meruli I represent nephrons that were not exposed to endothelin; Glomeruli II are nephrons that were infused with endothelin. (Bottom) Kidneys that underwent $25 \mathrm{~min}$ of ischemia $48 \mathrm{~h}$ before micropuncture. Glomeruli III are nephrons that during the micropuncture experiments were not exposed to endothelin antibody; Glomeruli IV are nephrons that were infused with endothelin antibody. This nomenclature for the different nephron populations is used in Table I and in the text. endothelin was similar to that observed in the absence of AII antagonist, 39 vs. $33 \%$ (Fig. 3). Similarly, $Q_{A}$ in these experiments fell by an average of $32 \%$ as compared with the $37 \%$ observed in Group 1. Both afferent and efferent arteriolar resistances increased significantly during systemic infusion of the AII antagonist, on average by 67 and 47\%, respectively. As in group 1 , there was no significant change in $K_{\mathrm{f}}$. Moreover, in these $\mathrm{Sar}^{1}-\mathrm{Thr}^{8}$ AII-treated rats, blanching of the kidney similar to that given in Fig. 1 occurred when endothelin was given in a comparable dose. To test the effectiveness of Sar ${ }^{1}-\mathrm{Thr}^{8}$ AII inhibition, exogenous AII was administered $(0.28 \mu \mathrm{g} / \mathrm{kg}$ body weight per $\mathrm{min}$ ) in a dose that previously increased systemic BP (13). The BP before and during administration of exogenous AII was $107 \pm 4 \mathrm{mmHg}$.

Table I describes microcirculatory dynamics of glomeruli in kidneys that underwent $25 \mathrm{~min}$ of ischemia $48 \mathrm{~h}$ before the micropuncture measurements and their response to endothelin antibody. Comparison with normal rats (baseline or noninfused values of Group 1) showed that the blood pressure and hematocrit were similar in the two groups of animals. Compared with normal kidneys, the hemodynamic pattern in the glomerular microcirculation of postischemic kidneys showed a typical hypoperfusion status. Thus, the lower levels of SNGFR and $Q_{\mathrm{A}}$ were noted in association with higher afferent and efferent arteriolar resistances than in normal undisturbed glomeruli (Glomeruli III vs. Glomeruli I). The glomerular capillary ultrafiltration coefficient $\left(K_{\mathrm{f}}\right)$ was also lower in the postischemic glomeruli than in normal glomeruli.

Table I also depicts the effects of antiendothelin antibody on glomerular hemodynamics. When vasoconstricted glomeruli in these previously injured kidneys were exposed to endothelin antibody, a remarkable amelioration in vasoconstriction occurred. Glomeruli infused with endothelin antibody (Glomeruli IV) had SNGFR values, on average, of 27.0 \pm 3.1 $\mathrm{nl} / \mathrm{min}$, compared with $17.4 \pm 1.7$ in glomeruli in areas not infused with the antiserum (Glomeruli III). Values for $Q_{\mathrm{A}}$ were almost 50\% higher in endothelin antibody-exposed glomeruli, reflecting lower arteriolar resistances, $R_{\mathrm{A}}$, on average of $0.59 \pm 0.08 \mathrm{~min} \cdot \mathrm{mmHg} / \mathrm{nl}$ vs. $0.24 \pm 0.03$ in the nonexposed glomeruli and $R_{\mathrm{E}}$ of $0.40 \pm 0.06$ vs. $0.21 \pm 0.03$. Although not shown in Table I, infusion of nonimmunized rabbit serum into five separate rats (body wt $251 \pm 37 \mathrm{~g}$ ) with postischemic kidneys, using the same infusion technique, caused no change in systemic or glomerular hemodynamics: SNGFR, 23.2 \pm 1.9 vs. $24.0 \pm 2.9 \mathrm{nl} / \mathrm{min} ; Q_{\mathrm{A}}, 97.4 \pm 17.3$ vs. $111.1 \pm 15.3 \mathrm{nl} / \mathrm{min}$; $P_{\mathrm{GC}} 49.0 \pm 1.0$ vs. $48.0 \pm 1.0 \mathrm{mmHg} ; P_{\mathrm{T}} 13.0 \pm 1.0$ vs. $12.0 \pm 1.0$ $\mathrm{mmHg}$.

\section{Discussion}

Given that the potential targets for endothelin actions include renal and nonrenal vasculature, we devised a method for agent administration that achieves a marked difference between local kidney and systemic circulating levels. For substances that are rapidly degraded within the circulation, use of the main renal artery as a route of administration will achieve comparable local concentrations in a dose approximating one-tenth of the systemically administered dose, because roughly $10 \%$ of cardiac output is delivered to one kidney. Given that one of the first-order branches of the main renal artery supplies approximately one-third of the nephron population within one kidney, the dosage required for similar local 
Table I. Summary of Systemic and Glomerular Microcirculatory Parameters in Groups 1 and 2

\begin{tabular}{|c|c|c|c|c|c|c|c|c|c|}
\hline & AP & Het & SNGFR & $Q_{A}$ & $P_{\mathrm{GC}}$ & $P_{\mathrm{T}}$ & $R_{\mathrm{A}}$ & $R_{\mathrm{E}}$ & $K_{f}$ \\
\hline & $m m H g$ & vol \% & & & & & & $\mid g / n l$ & $\mathrm{nl} / \mathrm{min} \cdot \mathrm{mmHg}$ \\
\hline \multicolumn{10}{|l|}{ Group 1} \\
\hline Noninfused & 105 & 46 & 35.9 & 153.0 & 51.3 & 14.1 & 0.21 & 0.15 & 3.44 \\
\hline (Glomeruli I) & \pm 3 & 1 & 4.3 & 22.9 & 1.5 & 1.0 & 0.03 & 0.02 & 0.84 \\
\hline Endothelin & 104 & 46 & $23.5^{*}$ & $95.9^{*}$ & $45.3^{*}$ & $11.3^{*}$ & $0.35^{*}$ & $0.22^{*}$ & 2.98 \\
\hline (Glomeruli II) & \pm 3 & 1 & 3.1 & 10.1 & 2.0 & 1.0 & 0.06 & 0.03 & 1.13 \\
\hline \multicolumn{10}{|l|}{ Group 2} \\
\hline Noninfused & 109 & 43 & $17.4^{\S}$ & $66.6^{\S}$ & 49.0 & 13.7 & $0.59^{\S}$ & $0.40^{\S}$ & $1.61^{\S}$ \\
\hline (Glomeruli III) & \pm 4 & 2 & 1.7 & 5.6 & 1.4 & 0.8 & 0.08 & 0.06 & 0.38 \\
\hline Endothelin antibody & 105 & 43 & $27.0^{\ddagger}$ & $128.7^{\ddagger}$ & $55.3^{\ddagger}$ & 13.1 & $0.24^{\ddagger}$ & $0.21^{\ddagger}$ & 1.43 \\
\hline (Glomeruli IV) & \pm 3 & 2 & 3.1 & 14.4 & 2.9 & 0.8 & 0.03 & 0.03 & 0.21 \\
\hline
\end{tabular}

Data presented for Group 1 ( $n=7$ rats) in which micropuncture data were obtained in nephrons not infused with endothelin (Glomeruli I) and nephrons exposed to endothelin (Glomeruli II). Also data from Group 2 ( $n=7$ rats) where micropuncture data were obtained in nephrons not infused with endothelin antibody (Glomeruli III) as well as nephrons exposed to endothelin antibody (Glomeruli IV). Values are expressed as mean \pm SEM. Efferent arteriolar colloid osmotic pressure-to-glomerular hydraulic pressure difference ratio in group 1 was $<1.0$ in five rats in the baseline and in five rats in the endothelin periods and in Group 2 this ratio was $<1.0$ in six rats in the baseline and in seven rats in the endothelin antibody periods. In these animals, unique $K_{\mathrm{f}}$ values were calculated and pooled with minimum $K_{\mathrm{f}}$ values to obtain average values. * Statistically significant differences $(P<0.05)$ between baseline and endothelin periods in Group $1 .{ }^{\ddagger}$ Statistically significant differences $(P$ $<0.05)$ between baseline and endothelin antibody periods in Group 2 . ${ }^{\S}$ Statistically significant differences $(P<0.05)$ between glomeruli I and glomeruli III. AP, arterial pressure; Hct, hematocrit.

concentration, delivered by this route is as little as one-thirtieth that required for systemic administration. In addition to minimizing activation of secondary mechanisms caused by the actions of endothelin in nonrenal organs, the branch infusion method provides other advantages: because the number of nephrons supplied by the branch artery is only a fraction of the entire nephron population, functional changes in these nephrons induced by branch injection of test agents are not expected to elicit appreciable compensatory changes in the remaining large nephron population, and allows simultaneous use of the remaining nephrons as controls. Moreover, nephrons directly supplied by the infused branch and nephrons exposed to systemic circulating level of the agent are present on the surface of the same kidney, allowing simultaneous assessment of glomerular microcirculatory dynamics in both nephron populations.

The branch infusion method posed two potential problems. First, the infusion pipette, itself, may alter the hemodynamics by hindering blood flow. Second, colloid-free and inulin-free infusate may confound calculations of SNGFR, filtration fraction and glomerular plasma flow rate. In this regard, the rate of infusion used in our study, i.e., $0.3 \mathrm{ml} / \mathrm{h}$, is approximately one-hundredth of the renal plasma flow rate, using $3.0-3.5 \mathrm{ml} / \mathrm{min}$ as a typical whole kidney plasma flow rate of

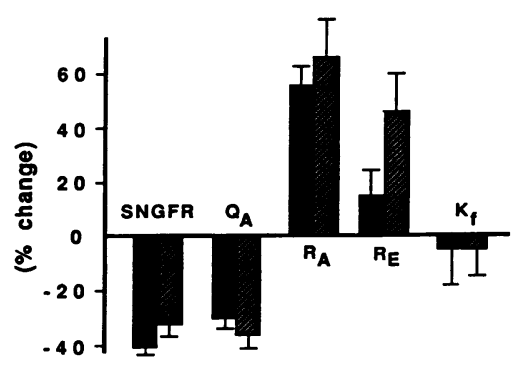

Figure 3. Comparison of endothelin effects in animals not treated (black bars) and treated (cross-hatched) with an AII antagonist, Sar ${ }^{1}$ $\mathrm{Thr}^{8}$ AII. the euvolemic rat. As described earlier, no appreciable differences/changes were detected with infusion of saline or nonimmunized plasma into the renal artery branch, attesting that the two potential artifacts have little influence on our overall data interpretation. This conclusion is also consistent with the notion that, due to their wide diameter, large vessels offer little hindrance to axial blood flow.

In an attempt to determine an appropriate dosage of endothelin to infuse via the renal artery branch we tested a wide range of dosages, i.e., $0.1-4.0 \mathrm{ng} / \mathrm{min}$. Because, experimental maneuvers that reduce glomerular perfusion by $>50 \%$ preclude reliable micropuncture measurements, due primarily to dissipation of pulsatile pressure tracing necessary to identify the glomerular capillary pressure, we chose $0.4 \mathrm{ng} / \mathrm{min}$. Higher dosages (as little as twofold higher), cause blanching of the kidney, making micropuncture assessment impossible.

In our experiments, we found reductions in SNGFR and $Q_{\mathrm{A}}$ by some $30 \%$ of their baseline levels. These changes were detected without alterations in systemic arterial pressure or arterial hematocrit, changes that were described in several studies performed with systemic intravenous infusion of endothelin (14-17). This pattern seen at single nephron level is in close agreement with that observed in the whole kidney obtained by Katoh et al. (18) who used intrarenal arterial infusion of endothelin in a dosage comparable to ours. Their study also found proportionally similar reductions in GFR and renal plasma flow rate without changes in systemic blood pressure or arterial hematocrit (Table II). The renal hemodynamic effects of human/porcine endothelin have simultaneously been reported by four other laboratories that examined the effects after systemic intravenous injection of endothelin (Table II). The results suggests that, in contrast to local administration, systemic administration of endothelin may affect glomerular filtration fraction to variable degrees. In the study by Banks (17), it was further noted that administration of an AII antagonist completely abolished the renal effect of systemically ad- 


\begin{tabular}{|c|c|c|c|c|c|}
\hline \multirow[b]{2}{*}{ Study } & \multirow[b]{2}{*}{ Route of administration } & \multirow[b]{2}{*}{ Dose } & \multicolumn{3}{|c|}{ Changes from baseline value } \\
\hline & & & SNGFR & $\operatorname{RPF}\left(Q_{\mathrm{A}}\right)$ & SNFF \\
\hline Present & Branch of main renal artery & $0.4 \mathrm{ng} / \mathrm{min}$ per branch & $-33 \%$ & $-37 \%$ & 0 \\
\hline Reference 18 & Main renal artery & $0.8-1.6 \mathrm{ng} / \mathrm{min}$ per kidney & $-31--79 \%$ & $-28--78 \%$ & 0 \\
\hline Reference 14 & Systemic intravenous & $50 \mathrm{ng} / \mathrm{kg}$ per $\min$ & $-98 \%$ & $-76 \%$ & -0.28 \\
\hline Reference 17 & Systemic intravenous & $120 \mathrm{ng} / \mathrm{kg}$ per $\mathrm{min}$ & $-74 \%$ & ND & ND \\
\hline Reference 15 & Systemic intravenous & $63-750 \mathrm{ng} / \mathrm{bolus}$ & $-8--67 \% *$ & $-17--89 \% *$ & $+0.03-+0.06^{*}$ \\
\hline Reference 16 & Systemic intravenous & $25 \mu \mathrm{g} /$ experiment & $-54 \%$ & $-34 \%$ & -0.09 \\
\hline
\end{tabular}

* Because absolute values are unavailable, these values were calculated, assuming baseline GFR and RPF to be 1.2 and $3.6 \mathrm{ml} / \mathrm{min}$, respectively, values typically found in normal adult euvolemic rats; in that study, 1,000 ng/bolus was found to reduce GFR and RPF to unmeasurable levels.

ministered endothelin. On the basis of their results, the authors concluded that the renal effects of endothelin (given systemically) are mediated entirely through activation of the reninangiotensin system. It is possible that systemic infusion of endothelin and/or larger doses of endothelin than given in the present study (Table II) may activate AII, which then has independent/additive effects on the hemodynamics within the systemic and renal circulations.

In this study, the greater than $30 \%$ reduction in SNGFR and plasma flow rate was associated with marked increase in arteriolar resistances, particularly within the afferent arteriole. The unique values for ultrafiltration coefficient were calculated in five rats and showed no appreciable effect of locally administered endothelin on $K_{\mathrm{f}}$. Although it is conceivable that higher doses of endothelin induce changes in $R_{\mathrm{A}}, R_{\mathrm{E}}$, and $K_{\mathrm{f}}$ in degrees different from the pattern found with our doses, it appears technically unfeasible to test such possibilities for the reasons discussed above. The hemodynamic pattern with local endothelin administration contrasts those describing the actions of exogenous AII. That is, AII causes marked reduction in ultrafiltration coefficient and also in arteriolar resistances $(13,19)$. Indeed, our additional study in a separate group of rats revealed that the glomerular microcirculatory effect of endothelin given locally is unaffected by an AII antagonist. Thus, with the dosage of AII antagonist used in this study (which has been shown to be effective in antagonizing local actions of endogenous AII in other experimental settings), there was no evidence to indicate that exogenous endothelin enhances local AII levels to a functionally significant extent.

In view of the previous observations that vasoconstrictors elaborated by the vascular endothelium are released in response to several potentially injurious stimuli including anoxia and hypoxia $(20,21)$, we also tested the possibility that the vasoconstriction that is characteristic of kidneys with previous ischemia is, in some part, due to endogenously released endothelin. In the nephrons infused with endothelin antibody there was a remarkable amelioration in the vasoconstriction. The glomeruli infused with antibody (Glomeruli IV, Fig. 2) but not those not exposed to antibody (Glomeruli III) showed an almost $60 \%$ increase in SNGFR and doubling in glomerular plasma flow rate. Compared with noninfused nephrons, there was an increase in the glomerular capillary pressure and fall in both afferent and efferent arteriolar resistances in these antibody infused glomeruli (Table I). These results are taken to be supportive for a role of endogenous endothelin in postischemic vasoconstriction.

This possibility is particularly attractive because in addition to describing endothelin as the most powerful vasoconstrictor of mammalian vessels, its effects were also shown to be long lasting. For example, systemic bolus injection of endothelin ( $1 \mathrm{nM}$ ) caused an elevation in blood pressure that lasted $>40$ min (1). In our pilot studies to determine the dosage for renal arterial branch infusion of endothelin, we often observed disappearance of blanching of the kidney within $\sim 20 \mathrm{~min}$ of cessation of endothelin administration. Our study with antiendothelin antibody infusion also demonstrated improvement of glomerular hypoperfusion and hypofiltration in postischemic kidneys toward normal control levels. In addition to the long lasting effects of endothelin, evidence is accumulating suggesting that renal vascular endothelial cells are morphologically abnormal to a variable extent in some forms of acute renal failure (22-24), which may alter endothelial function, including activation or release of vasoconstrictor substances. It is conceivable, then, that renal injuries, including ischemia, may induce functionally profound alterations of the endothelial cell metabolism, which involves enhancement of endothelin release, thereby contributing to the persistent renal vasoconstriction typical even after resolution of the renal insult.

\section{Acknowledgments}

The authors thank M. Laurette Hughes, Brad Harvie, and Teresa Bills for technical assistance and Mary E. Yeomans and Mary Beehan for secretarial work.

Dr. Ichikawa is a recipient of the Established Investigatorship Award from the American Heart Association. These studies were supported by the National Institutes of Health grants DK-37869, DK-40527, and DK-39547.

\section{References}

1. Yanagisawa, M., H. Kurihara, S. Kimura, Y. Tomobe, M. Kobayashi, Y. Mitsui, Y. Yazaki, K. Goto, and T. Masaki. 1988. A novel potent vasoconstrictor peptide produced by vascular endothelial cells. Nature (Lond.). 332:411-415.

2. Lee, C. Y., and V. A. Chiappinelli. 1988. Scientific correspondence. Nature (Lond.). 335:303.

3. Takasaki, C., M. Yanagisawa, S. Kimura, K. Goto, and T. Masaki. 1988. Scientific correspondence. Nature (Lond.). 335:303. 
4. Kon, V., M. L. Hughes, and I. Ichikawa. 1983. Blood flow dependence of postglomerular fluid transfer and glomerulotubular balance. J. Clin. Invest. 72:1716-1728.

5. Ichikawa, I., D. A. Maddox, M. G. Cogan, and B. M. Brenner. 1978. Dynamics of glomerular ultrafiltration in euvolemic MunichWistar rats. Renal Physiol. 1:121-131.

6. Deen, W. M., J. L. Troy, C. R. Robertson, and B. M. Brenner. 1973. Dynamics of glomerular ultrafiltration in the rat. IV. Determination of the ultrafiltration coefficient. J. Clin. Invest. 42:1500-1508.

7. Ichikawa, I. 1982. Direct analysis of the effector mechanism of the tubuloglomerular feedback system. Am. J. Physiol. 243:F447F455.

8. Führ, J., J. Kaczmarczyk, and C. D. Krüttgen. 1955. Eine einfache colorimetrische Methode zur Inunlinbestimmung für Nierenclearanceuntersuchungen bei Stoffwechselgesunden und Diabetikern Klin. Wochenschr. 33:729-730.

9. Vurek, G. G., and S. E. Pegram. 1966. Fluorometric method for the determination of nanogram quantities of inulin. Anal. Biochem. 16:409-419.

10. Viets, J. W., W. M. Deen, J. L. Troy, and B. M. Brenner. 1978. Determination of serum protein concentration in nanoliter blood samples using fluorescamine or o-phthalaldehyde. Anal. Biochem. 88:513-521.

11. Wallenstein, S., C. L. Zucker, and J. Fleiss. 1980. Some statistical methods useful in circulation research. Circ. Res. 47:1-9.

12. Kon, V., M. L. Hughes, and I. Ichikawa. 1984. Physiologic basis for the maintenance of glomerulotubular balance in young growing rats. Kidney Int. 25:391-396.

13. Schor, N., I. Ichikawa, and B. M. Brenner. 1980. Glomerular adaptations to chronic dietary salt restriction or excess. Am. J. Physiol. 238:F428-436.

14. Miller, W. L., M. Redfield, and J. C. Burnett. 1988. Endothelin constricts the renal circulation and stimulates renin in vivo. Kidney Int. 35:317. (Abstr.)
15. King, A. J., S. Anderson, and B. M. Brenner. 1988. Systemic and renal vasoconstrictive effects of endothelin. Kidney Int. 35:314. (Abstr.)

16. Badr, K. F., M. D. Breyer, K. Takahashi, J. J. Murray. M. Schwartzberg, J. Ebert, T. Inagami, and R. C. Harris. 1988. Mesangial cell (MC), glomerular, and renal vascular responses to endothelin (EN) in the rat. Kidney Int. 35:308. (Abstr.)

17. Banks, R. O. 1988. Cardiovascular and renal effects of endothelin (EN) in the dog and in the rat. Kidney Int. 35:309. (Abstr.)

18. Katoh, T., H. Chang, T. Okuda, S. Uchida, and K. Kurokawa. 1988. Endothelin decreases urine volume, GFR, and RPF by its direct action on the kidney, but does not affect mesangial cell function. Kidney Int. 35:313. (Abstr.)

19. Blantz, R. C, K. S. Konnen, and B. J. Tucker. 1976. Angiotensin II effects upon the glomerular microcirculation and ultrafiltration coefficient in the rat. J. Clin. Invest. 57:419-434.

20. Rubanyi, G. M., and P. M. Vanhoutte. 1985. Hypoxia releases a vasoconstrictor substance from the canine vascular endothelium. $J$. Physiol. (Lond.). 364:45-56.

21. DeMey, J. G., and P. M. Vanhoutte. 1983. Anoxia and endothelium-dependent reactivity of the canine femoral artery. J. Physiol. (Lond.). 335:65-74.

22. Williams, R. J., C. E. Thomas, L. G. Navar, and A. P. Evan. 1981. Hemodynamic and single nephron function during the maintenance phase of ischemic acute renal failure in the dog. Kidney Int. 19:503-515.

23. Gattone, V. H. II, A. P. Evan, S. A. Mong, B. A. Connors, G. R. Aronoff, and F. C. Luft. 1983. The morphology of the renal microvasculature in glycerol- and gentamicin-induced acute renal failure. $J$. Lab. Clin. Med. 101:183-195.

24. Kobayashi, S., M. Nagase, N. Honda, and A. Hishida. 1984. Glomerular alterations in uranyl acetate-induced acute renal failure in rabbits. Kidney Int. 26:808-815. 